\title{
Assessment of Varieties of Spring Barley of Selection of Omsk Agrarian Research Center for Adaptivity of Mass of 1000 Grains
}

\author{
P N Nikolaev1, O A Yusova1, N | Aniskov², and || V Safonova² \\ ${ }^{1}$ Omsk Agrarian Scientific Center, Omsk, Russia \\ ${ }^{2}$ Federal Research Center All-Russian Institute of Plant Genetic Resources named after N.I. \\ Vavilova, St. Petersburg, Russia
}

\section{Abstract}

Considering climatic factors and production demands, selection for increased productivity and adaptability to local climatic factors is currently relevant. To create new varieties of barley with the listed factors, a promising source material with improved adaptive qualities is required. One of the leading structural elements that determine the productivity of a variety is the mass of 1000 grains. Objective: to assess the adaptability of spring barley varieties from the selection of the Omsk Agrarian Scientific Center in

Corresponding Author:

P N Nikolaev

ksanajusva@rambler.ru

Received: 25 October 2019

Accepted: 15 November 2019

Published: 25 November 2019

Publishing services provided by Knowledge E

(c) P N Nikolaev et al. This article is distributed under the terms of the Creative Commons

Attribution License, which permits unrestricted use and redistribution provided that the original author and source are credited.

Selection and Peer-review under the responsibility of the AgroSMART 2019 Conference Committee. terms of the mass of 1000 grains. The object of research was 11 varieties of spring barley breeding Omsk Agrarian Scientific Center. Based on this indicator, the following adaptability parameters were calculated: the indicator of the size of the grain size, the coefficient of variation, the coefficient and ecovalent of ecological plasticity, the relative stability of the trait and homeostaticity. The final assessment was carried out according to the sum of ranks obtained by each applied method, given that rank 1 is higher. The average weight of 1000 grains of barley varieties, breeding of the Omsk ANC, was $45.7 \mathrm{~g}$ in membranous and $40.9 \mathrm{~g}$ in huskless. According to the results of adaptability studies, stable varieties were identified that are poorly responsive to changes in cultivation conditions and better adapted to medium and low levels of agriculture: Omsky 95, Gift of Siberia and Omsk huskless 2 (the sum of ranks ranged from 22.0 to 29.0). Varieties Sibirsky Avant-garde, Sasha, Omsky 91, Omskyhuskless 1 and Omsky 90 (sum of ranks from 38.0 to 51.0) are classified as plastic ones -- the change in grain size of these varieties is fully consistent with the change in growing conditions. Strong responsiveness to changing conditions was found in varieties Omsky 96, Omsky 100 and Omsky 99 (the sum of ranks varies from 59.0 to 63.0) -- these varieties belong to the intensive group, which means less adaptability to adverse conditions.

Keywords: spring barley, coefficient of variation, adaptability, stability, plasticity, homeostaticity.

\section{Introduction}

One of the most urgent topics of discussion of the present is the problem of observed G OPEN ACCESS 
4]. Climatic metamorphoses over the past decade led to changes in phytocenoses, which was manifested in the negative effect of productivity of crops. In connection with global climate change, the problem of creating and using varieties with increased adaptive properties, which is a key factor for a stable increase in both yield and quality of agricultural products, is becoming particularly urgent.

Such an irreplaceable, by its extremely diverse use, cereal crops, such as barley, are quite common in the Russian Federation (North Caucasus, Urals, Siberia, Central Black Earth and Non-chernozem zones) [5] due to such reasons as the formation of increased productivity (compared to other forage crops) due to early maturity and drought tolerance [6--8].

Considering climatic factors and production demands, selection is currently relevant for increased productivity and adaptability to local climatic factors [9, 10], ecological plasticity, and resistance to biotic and abiotic stresses [11, 12]. To create new varieties of barley with the listed factors, a promising source material with improved adaptive qualities is required.

Currently, the presence of only high potential productivity in new varieties is not enough, it should also be accompanied by adaptability [13], which is the main condition for identifying the ecological niche of each variety with a view to its introduction into production.

Objective: to assess the adaptability of spring barley varieties from the selection of the Omsk Agrarian Scientific Center according to the indicator "mass of 1000 grains".

The object of research was 11 varieties of spring barley breeding Omsk Agrarian Scientific Center.

\section{Materials and Methods}

The adaptability of barley was calculated by the following indicators:

The coefficient of variation:

$$
C V=\frac{S}{\bar{x}} \times 100 \%,
$$

where $\mathrm{CV}$ is the standard deviation, expressed as a percentage of the arithmetic mean of the given population; $\mathrm{S}$ is the standard deviation; $\mathrm{x}^{-}$is the arithmetic average of the mass of 1000 grains.

The coefficient of environmental plasticity:

$$
O=\frac{\bar{m}}{\sigma}
$$


where $\mathrm{O}$ is the coefficient of ecological plasticity, $\bar{M}$ is the average mass of 1000 grains, бis the standard deviation.

Relative stability of the trait:

$$
S t^{2}=\frac{\overline{x^{2}}-S^{2}}{\overline{x^{2}}}
$$

where $\mathrm{St}^{2}$ is the relative stability of the sign; $\mathrm{x}^{2^{-}}$-- average weight of 1000 grains; $\mathrm{S}^{2}$ the total dispersion of the mass of 1000 grains of the studied variety

Homeostatic:

$$
H o m=\frac{\bar{x}}{C V},
$$

where Hom is the homeostatic nature of the variety, $\bar{x}$ is the arithmetic average of the mass of 1000 grains; CV -- coefficient of variation of grain.

Ecovalent environmental plasticity:

$$
\begin{gathered}
W_{i}=\sum l^{2}{ }_{i j}, \\
l_{i j}=\bar{x}_{i j}-\bar{x}_{i}-\bar{x}_{j}+\bar{x}_{\ldots \ldots},
\end{gathered}
$$

where $\bar{x}_{i j}$ is the mass of 1000 grains of the $\mathrm{i}$-th grade in the $\mathrm{j}$-th year; $\bar{x}_{i}$-mass of 1000 grains of the $\mathrm{i}$-th grade; $\bar{x}_{j}$ is the average mass of 1000 grains in the jth year; $\bar{x} \ldots$ is the average mass of 1000 grains in the experiment.

The indicator of the size of the grain size.

$$
d=\operatorname{Ymax}-Y \min ,
$$

where Ymax is the maximum mass of 1000 grains; Ymin is the minimum mass of 1000 grains.

\section{Results and Discussion}

One of the leading structural elements that determine the productivity of a variety is the mass of 1000 grains. This indicator characterizes the coarseness and density of grain -- with an increase in the mass of 1000 grains, its coarseness and completeness increases.

The results of evaluating the grain size of barley varieties, breeding of the Omsk ANC showed that the average weight of 1000 grains of the membranous varieties were $45.7 \mathrm{~g}$, of the bare grains -- $40.9 \mathrm{~g}$, tab. 1. The standard variety Omsky $95(43.98 \mathrm{~g})$ 
of the varieties Sibirsky Vanguard, Sasha, Omsky 90 and Omsky $96(+2.39 \ldots+5.50 \mathrm{~g})$ exceeded the standard variety Omsky 95 (43.98 g).

The current level of agriculture does not yet correspond to the level at which the action of adverse agroecological factors will not have a decisive influence on the formation of productivity and quality of cultivated varieties. Therefore, varieties must combine adaptability to limiting environmental factors $[14,15]$ with responsiveness to improved cultivation conditions

A reliable assessment of the adaptive potential of the studied varieties requires their environmental testing by various static assessment methods [14, 15]. One of such methods for calculating the level of stability of varieties is a measure of the size of the grain size (d), which shows the ratio of the difference between Max and Min grain size of the variety to the maximum, expressed as a percentage. The lower this indicator, the more stable the mass of 1000 grains of the variety in specific conditions. The presented criteria correspond to the membranous variety Gift of Siberia $\left(Y_{\max }-Y_{\min }=15,27 \mathrm{~g}\right)$ and Omsk huskless 1 ( $Y_{\max }-Y_{\min }=12,46 \mathrm{~g}$ ), meet the above criteria, which is 28.6 and $29.6 \%$, respectively. Thus, the realization of the potential for grain size assumes the maximum experience value for these varieties (90.5 and $88.5 \%$ ).

$Y_{\min }, Y_{\max }$ the minimum and maximum grain size, $\mathrm{d}$ is the magnitude of grain size, $\mathrm{S} \bar{x}$ -- relative attribute error; $\bar{x}$-- average value of the attribute.

Often, the underestimation of the importance of studies on the ecological plasticity of varieties can manifest itself in such a negative, from the point of view of breeding practice, phenomenon, such as low realization of productivity in difficult climatic conditions [16].

Improving the environmental sustainability of varieties, which means increasing their ability to ensure high and stable productivity regardless of growing conditions, is a fundamental selection task both in Russian [17] and in world practice [18-21].

The indicated ability is determined by the rate of response of the variety genotype to environmental factors. In the absence of a genetic reaction of the variety to soil-climatic conditions (narrow environmental sustainability), this variety is characterized as resistant to various biotic and abiotic stresses. One of the characteristics of variability is the coefficient of variation [22]. The stability of the genotype will increase with a decrease in its variability, which, in turn, may adversely affect its adaptive qualities when cultivated in other climatic zones. In our case, the variability of all studied varieties is average (CV $>10 \%$ ), close to significant ( $C V=16.3 . .18 .9 \%$ ) for varieties Omsky 91, Omsky 96, Omsky 99 and Omsky 100 -- which indicates the response of the listed varieties to change the growing conditions, table. 2. 


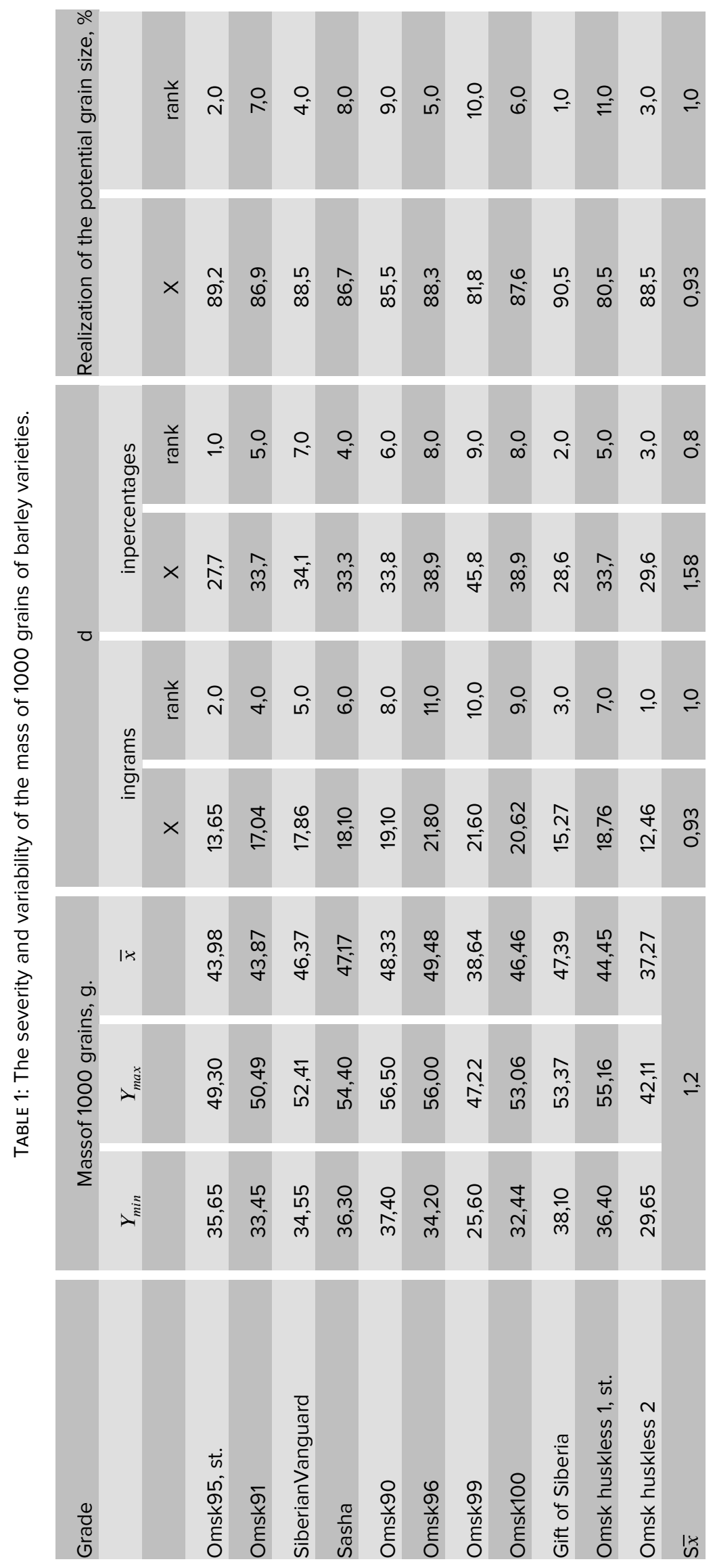


To assess the response of the variety genotype to environmental factors, plasticity indicators help. Thus, in most cases, coarse grains of Omsky 95, Sibirsky Vanguard, Sasha and Gift of Siberia varieties stably stably formed $(\mathrm{O}=7.04 \ldots 9.16 ; \mathrm{Wi}=19.73 \ldots 27.56)$, the low ecovalent of plasticity of these varieties indicates the possibility of forming larger grains in adverse conditions. A high ecovalent of the varieties Omsk Golozerny 1, Omsk Golozerny 2, Omsk 100, Omsk 99 and Omsk 96 (Wi = 91.4...135.7) means the possibility of the formation of large grains in favorable growing conditions.

An indicator of stability $\left(\mathrm{St}^{2}\right)$ plays an important role in assessing the adaptability of varieties. Barley varieties with a special combination of productivity and stability under various weather conditions acquire a special status [23]. The value of the $\mathrm{St}^{2}$ indicator varies from 0 to 1 , the higher the stability indicator, the more often the variety can form large grains. The calculated parameter demonstrates the stability of the formation of large grains in the varieties Omsky 95 and Omsk huskless $2\left(\mathrm{St}^{2}=0,99\right)$, the stability level of the remaining studied varieties is slightly lower than the standard $\left(\mathrm{St}^{2}<0,99\right)$.

One of the parameters that certifies the resistance of varieties to the effects of adverse environmental factors is homeostasis, which represents the ability of the genotype to minimize the effects of adverse conditions. The manifestation of high homeostiticity is associated with less variability in grain size under varying environmental conditions. In our work, the varieties Omsky 99, Omsky 100, Omsky 91, and Omsky 96 (Hom $=2.23 \ldots .2 .93$ ) are the most resistant to changes in growing conditions based on the weight of 1000 grains.

According to modern researchers, the classification of the behavior of genotypes under various environmental conditions by one or two methods is insufficient to characterize their adaptability. To solve this problem, it is necessary to consider that different methods evaluate different aspects of the adaptive ability of varieties, and therefore it is necessary to use a number of methods according to the ranking principle [24, 25]. The final assessment is carried out by the sum of the ranks obtained by each applied method (Tables 1, 2), given that rank 1 is higher.

Three groups of varieties were distinguished by the sum of adaptability ranks:

1. Stable varieties, poorly responsive to changes in cultivation conditions: Omsky 95, Gift of Siberia, Omsk huskless 2 ( $\sum$ ranks $=22.0 \ldots$.29.0). These varieties are better adapted to medium and low levels of agriculture, which must be considered in production conditions. 
TABLE 2: Adaptability barley by weight of 1000 grains.

Grade
Omsk 95, st.
Omsk 91
SiberianVanguard
Sasha
Omsk90
Omsk 96
Omsk 99
Omsk 100
Gift of Siberia
Omskhuskless 1, st.
Omskhuskless 2
S $\bar{x}$

\begin{tabular}{|c|c|c|c|c|c|c|c|c|c|c|}
\hline \multicolumn{2}{|c|}{ CV, \% } & \multicolumn{2}{|c|}{0} & \multicolumn{2}{|c|}{$\mathrm{St}^{2}$} & \multicolumn{2}{|c|}{ Hom } & \multicolumn{2}{|c|}{ Wi } & \multirow{2}{*}{$\sum_{\text {grades }}$} \\
\hline$x$ & rank & $x$ & rank & $x$ & rank & $X$ & rank & $x$ & rank & \\
\hline 10,9 & 2,0 & 9,16 & 2,0 & 0,99 & 1,0 & 4,03 & 11,0 & 19,73 & 1,0 & 22,0 \\
\hline 16,3 & 8,0 & 6,13 & 8,0 & 0,97 & 3,0 & 2,69 & 3,0 & 38,95 & 5,0 & 43,0 \\
\hline 13,6 & 4,0 & 7,36 & 4,0 & 0,98 & 2,0 & 3,41 & 8,0 & 27,56 & 4,0 & 38,0 \\
\hline 14,2 & 6,0 & 7,04 & 6,0 & 0,98 & 2,0 & 3,32 & 7,0 & 24,40 & 3,0 & 42,0 \\
\hline 14,7 & 7,0 & 6,81 & 7,0 & 0,98 & 2,0 & 3,29 & 6,0 & 44,54 & 6,0 & 51,0 \\
\hline 16,9 & 9,0 & 5,96 & 9,0 & 0,97 & 3,0 & 2,93 & 4,0 & 135,7 & 11,0 & 60,0 \\
\hline 17,3 & 10,0 & 5,77 & 10,0 & 0,97 & 3,0 & 2,23 & 1,0 & 134,1 & 10,0 & 63,0 \\
\hline 18,9 & 11,0 & 5,28 & 11,0 & 0,96 & 4,0 & 2,46 & 2,0 & 119,9 & 8,0 & 59,0 \\
\hline 13,5 & 3,0 & 7,52 & 3,0 & 0,98 & 2,0 & 3,51 & 9,0 & 21,87 & 2,0 & 25,0 \\
\hline 14,1 & 5,0 & 7,17 & 5,0 & 0,98 & 2,0 & 3,15 & 5,0 & 91,7 & 7,0 & 47,0 \\
\hline 10,4 & 1,0 & 9,50 & 1,0 & 0,99 & 1,0 & 3,58 & 10,0 & 122,9 & 9,0 & 29,0 \\
\hline 0,8 & 1,0 & 0,4 & 1,0 & 0,01 & 0,27 & 0,16 & 1,0 & 14,9 & 1,0 & 4,3 \\
\hline
\end{tabular}

Note: $\mathrm{X}$ is the value of the adaptability indicator; $\mathrm{S} \bar{x}$-- relative attribute error; $\sum$-- amount; CV -coefficient of variation; $\mathrm{O}$ is the coefficient of environmental plasticity; Wi -- Ecovalent Plasticity; $\mathrm{St}^{2}$-relative stability; Hom -- homeostatic.

2. The following varieties are classified as plastic: Sibirsky Vanguard, Sasha, Omsky 91, Omsk huskless 1, Omsky 90. The change in grain size of these varieties fully corresponds to the change in growing conditions $\left(\sum\right.$ ranks $\left.=38.0 \ldots 51.0\right)$.

3. Strong responsiveness to changing conditions was found in varieties Omsky 96, Omsky 100, Omsky 99 ( $\sum$ ranks $\left.=59.0 . .63 .0\right)$. These varieties belong to the intensive group, which means less adaptability to adverse conditions.

\section{Conclusions}

1. The average weight of 1000 grains of barley varieties, breeding of the Omsk ANC, was $45.7 \mathrm{~g}$ in membranous and $40.9 \mathrm{~g}$ in bare grain.

2. Stable varieties include Omsk 95, Gift of Siberia and Omsk huskless 2.

3. To plastic ones -- the Siberian Vanguard, Sasha, Omsk 91, Omsk huskless 1 and Omsk 90.

4. Intensive -- Omsk 96, Omsk 100 and Omsk 99. 


\section{Financing}

The work was performed as part of a state assignment:

1. Federal State Budget Scientific Institution "Omsk Agrarian Scientific Center" on assignment No. 0797-2019-0009 "Creation of new varieties of leguminous crops (peas and soybeans), grain fodder (barley, oats) and perennial grasses (alfalfa, beetless boneless) with improved productivity indicators and quality, increased resistance to disease, to adverse biotic and abiotic environmental factors. " (Direction of science $X 10.4$. Crop production, paragraph No. 150 of the program of the FNI State Academy for 2013--2020);

2. Federal Research Center "All-Russian Institute of Plant Genetic Resources named after N.I. Vavilova "on assignment No. 0662-2019-0006" Search, maintenance of viability and unleashing the potential of hereditary variability of the world collection of cereals and cereals All-Union Research Institute of Plant Breeding for development, optimized genebank and rational use in breeding and plant growing".

\section{The Confirmation}

The authors would like to thank their colleagues for their contribution and support in the study. They are also grateful to all reviewers for their valuable manuscript writing tips and assistance in completing the study.

\section{Conflict of Interest}

The authors declare no conflict of interest.

\section{References}

[1] Labudová, L., Faško, P., Ivanáková, G. (2015). Changes in climate and changing climate regions in slovakia. Moravian Geographical Reports, vol. 23 (3), pp. 70--81.

[2] Perdinan, P., Winkler, J.A. (2014). Changing human landscapes under a Changing climate: considerations for Climate assessments. Environmental Management, vol. 53(1), pp. 42--54.

[3] Lloret, F., Martínez-Vilalta, J. et al. (2012). Extreme Climatic events and vegetation: the role of stabilizing Processes. Global Change Biology, vol. 18 (3), pp. 797--805. 
[4] Lipka, O.N. (2017). Methodological approaches to Climate change vulnerability assessment of Protected areas. Nature Conservation Research, vol. 2(3), pp. 68-79.

[5] Kuzina, E.V., Davletshin, T.K., Silishchev, N.N. et al. (2010). Effectiveness of the Elena Biopreparation used forgrowing the summer Barley. Agricultural Biology, vol. 4, pp. 100--104.

[6] Yadav, R.R. (2015). Tree-ring Footprints of Drought variability In Last 300 years over Kumaun Himalaya, India and its relationship with crop Productivity. Quaternary Science Reviews, vol. 117, pp. 113--123. DOI: 10.1016/j.quascirev.2015.04.003.

[7] Khokhar, M.I., Da Silva, J.A.T. (2012). Evaluation of Drought Tolerance and Yield Capacity of Barley (Hordeum Vulgare) Genotypes under irrigated And WaterStressed Conditions. Pakistan Journal of Agricultural Sciences, vol. 3(49), pp. 307-313.

[8] Rapacz, M. Stepień, A., Skorupa, K. (2012). Internal Standards for quantitative rt-pcr studies of gene expression under drought Treatment in Barley (hordeum vulgare I.): the Effects of developmental Stage and Leaf Age. Acta Physiologiae Plantarum, vol. 5(64), pp. 1723--1733. DOI: 10.1007/s11738-012-0967-1.

[9] Karsai, M.L. (2001) Multivariate Analysis of Traits determining Adaptation in cultivated Barley. Plant Breeding, vol. 120(3), pp. 217--222. DOI: 10.1046/j.14390523.2001.00599.x.

[10] Potanin, W.G., Aleinikov, A.F., Stepochkin, P.I. (2014). A new Approach to estimation of the Ecological Plasticity of plant Varieties. Vavilov Journal of Genetics and Breeding, vol. 18(3), pp. 548--552.

[11] Robinson, L.H., Lahnstein, J., Eglinton, J.K. (2007). The Identification of a Barley Haze active Protein that influences Beer haze stability: Cloning and Characterisation of the Barley se Protein as a Barley Trypsin Inhibitor of the Chloroform. Methanol Type. Journal of Cereal Science, vol. 45(3), pp. 343--352. DOI: 10.1016/j.jcs.2006.08.012.

[12] Sarkar, B. (2014). Identifying Superior feed Barley Genotypes using gge biplot for diverse Environments in India. Indian Journal of Genetics and Plant Breeding, vol. 1(74), pp. 26--33. DOI: 10.5958/j.0975-6906.74.1.004.

[13] Nevo, E. (2015). Evolution of wild Barley at "Evolution Canyon": Adaptation, speciation, pre-agricultural collection, and Barley improvement. Israel Journal of Plant Sciences, vol. 62(1-2), pp. 22--32. DOI: 10.1080/07929978.2014.940783.

[14] Kadi, Z., Adjel, F., Bouzerzour, H. (2010). Analysis of the genotype x environment interaction of barley grain yield (Hordeum vulgare L.) under semi-arid conditions. Advances in Environmental Biology, vol. 4(1), pp. 34--40. 
[15] Saad, F.F., El-Mohsen, A.A., Al-Soudan, I.H. (2013). Parametric statistical methods for evaluating barley genotypes in multienvironment trials. World Essays Journal, vol. 1(4), pp. 125--136.

[16] Sadras, V.O. Slafer, G.A. (2012). Environmental Modulation of yield Components in cereals: Heritabilities Reveal a hierarchy of Phenotypic Plasticities. Field crops Research, vol. 127, pp. 215--224. DOI: 10.1016/j.fcr.2011.11.014.

[17] Rubas', I.A. (2016). Increased adaptivity in grain selection. agricultural biology, vol. 51(5), pp. 617--626.

[18] Mohamed Ahmed, S.B., Abdella, A.W.H. (2009). Genetic yield stability in some sunflower (Helianthus annuus L.) hybrids under different environmental conditions of Sudan. Plant Breed.Crop Sci., vol. 1 (1), pp. 016--021.

[19] Mut, Z., Aydin, N., Bayramoglu, H.O. et al. (2010). Stability of some quality traits in bread wheat (Triticum aestivum) genotypes. Journal of Environmental Biology, vol. 31, pp. 489--495.

[20] Das, S., Misra, R.C., Sinha, S.K. et al. (2010). Variation in streptomycin-induced bleaching and dark induced senescence of rice (Oryza sativa) genotypes and their relationship with yield and adaptability. Plant Breed. Crop Sci., vol. 2(6), pp. 139--147.

[21] Raja, S., Bagle, B.G., More, T.A. (2013). Drumstick (Moringa oleifera Lamk.) improvement for semiarid and arid ecosystem: analysis of environmental stability for yield. Plant Breed. Crop Sci., vol. 5(8), pp. 164--170.

[22] Abdul-Razzak Tahir, N. (2014). Comparison of Rapd-PCR and SDS-Page Techniques to Evaluate Genetic Variation among nine Barley Varieties (Hordeum SPP). Malaysian Applied Biology, vol. 43(1), pp. 107--117.

[23] Hudzenko, V.M., Demydov, O.A., Vasylkivskyi, S.P. (2017). Graphical analysis of adaptability of spring barley breeding lines in the Central Forest-Steppe zone of Ukraine. Plant Varieties Studiyng and Protection, vol. 13(1), pp. 20--24. DOI: 10.21498/2518-1017.1.2017.97233.

[24] Popolzukhin, P.V., Nikolaev, P.N., Anis'kov, N.I., et al. (2018). Evaluation of Productivity and Adaptive Properties of Spring Barley Varieties under Conditions of the Siberian Irtysh Region. Zemledelie, vol. 3, pp. 40--43. DOI: 10.24411/0044-3913-2018-10309.

[25] Popolzukhin, P.V., Nikolaev, P.N., Anis'kov, N.I., et al. (2019). Agrobiological Characteristics of Fodder Spring Barley 'Sasha'. Achievements of Science and Technology of A/Cis. vol. 1, pp. 27--29. DOI: 10.24411/0235-2451-2019-10106. 